\title{
ПОЛУЧЕНИЕ ВОЛОКНА НА ОСНОВЕ СОПОЛИМЕРА АКРИЛОНИТРИЛА И МЕТАКРОЛЕИНА
}

\author{
А. КОльК
}

\author{
А. КОНКин, 3. РОГОвин, \\ доктора технических наук
}

Модификации полиакрилонитрила (ПАН) посвящено большое число работ. Введение в макромолекулу ПАН реакционноспссобных альдегидных групп позволяет і широких пределах изменять свойства ПАН и полученного из него волокна. Ранес описан метод синтеза сополимера (ПАНМ) акрилонитрила (АН) с метакролеином (MA) и исследованы основные закономерности сополимеризации этой пары мономеFов [1]. Данная работа посвящена нахождению условий синтеза волокнообразующих сополимеров и исследованию возможностей формования волокон на его основе. Қонстанты сополимеризации АН и $\mathrm{MA}\left(r_{1}=0,15 \pm 0,04 ; r_{2}=1,7 \pm 0,3\right)$ [1] указывают на бо́льшую реакционную способность МА при взаимодействии как с радикалом МА, так и с радикалом АН. Различие в реакционной способности данной пары мономеров обусловливает неравномерное расходование их в. ходе реакции, что приводит к изменению состава сополимера, образующего на различных стадиях завершенности реакции. При неглубоких степенях превращения, химический состав сополимера колеблется незначительно, однако при проведении процесса сополимеризации до выхода 60-70\% спстав полученного сополимера значительно изменяется. На рис. 1 приве дены изменения дифференциального и интегрального составов сополимера ПАНМ в процессе сополимеризации. Расчет был выполнен по методу, описанному в работах $[2,3\}$.

Для сополимера ПАНМ (в соотношении АН : $\mathrm{AA}=95: 5$ вес. \%) был разрабо тан способ синтеза с дробной дозировкой смеси мономеров во время реакции.

Рис. 1. Интегральный и дифференциальный составы сополимера ПАНМ

- - интегральный состав (рассчитанный по полному уравнению),

дифференциальный состав (рассчитанный по полному уравнению),

- экспериментально найденный состав сополимера, синтезированного в водной среде,

- экспериментально найденный состав сополимера, синтезированного в бензольной среде.

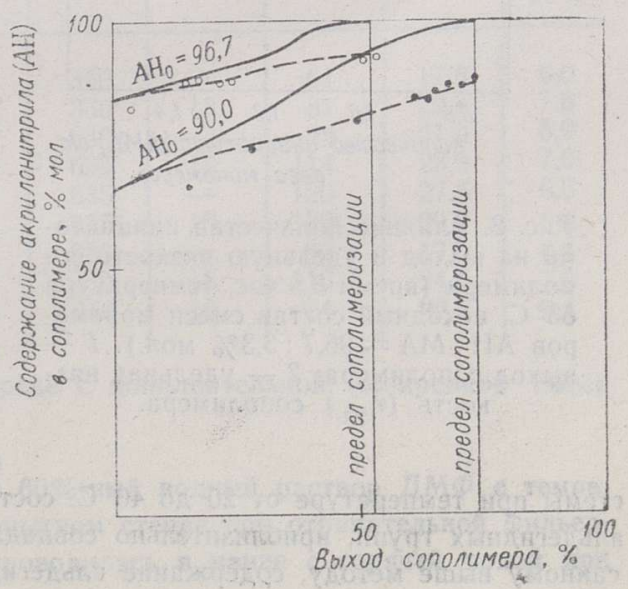


Сополимеризация АН с МА с дробной дозировкой смеси мономеров и без дозировки (соотношение мономеров АН: $\mathrm{AA}=99: 1 \%$ мол., количество регулятора $1 \%$, количество инициатора $2 \%$, температура $40^{\circ}$. Полимеризация проводилась в $7 \%$-ном водном растворе мономеров)

\begin{tabular}{|c|c|c|c|c|c|c|c|c|c|}
\hline \multirow[b]{2}{*}{$\begin{array}{l}\text { 스 } \\
\text { пा. }\end{array}$} & \multirow[b]{2}{*}{ 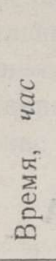 } & \multicolumn{4}{|c|}{$\begin{array}{c}\text { Сополимеризация без дозировки } \\
\text { смеси мономеров }\end{array}$} & \multicolumn{4}{|c|}{$\begin{array}{c}\text { Сополимеризация с дозировкой } \\
\text { смеси мономеров * }\end{array}$} \\
\hline & & $\begin{array}{l}\dot{8} \\
0 \\
\frac{x}{1} \\
\text { ma }\end{array}$ & $\begin{array}{l}\text { Содержа- } \\
\text { ние N, \% }\end{array}$ & $\begin{array}{c}\text { Состав } \\
\text { сополи- } \\
\text { мера } \\
(\mathrm{AH}: \mathrm{MA}) \\
\text { вес. } \%\end{array}$ & $\begin{array}{c}\text { Уделіная } \\
\text { вязкость } \\
\text { (Пуд.) }\end{array}$ & 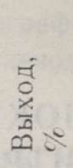 & $\begin{array}{l}\text { Содержа- } \\
\text { ние N, \% }\end{array}$ & $\begin{array}{c}\text { Состав } \\
\text { сополи. } \\
\text { мера } \\
(\mathrm{AH}: M A) \\
\text { вес. } \%\end{array}$ & $\begin{array}{c}\text { Удельная } \\
\text { вязкостц } \\
\left(\eta_{\text {ду. }}\right)\end{array}$ \\
\hline $\begin{array}{l}1 \\
2 \\
3\end{array}$ & $\begin{array}{l}1 \\
2 \\
3\end{array}$ & $\begin{array}{l}10 \\
19 \\
42\end{array}$ & $\begin{array}{l}24,7 \\
25.1 \\
25,5\end{array}$ & $\begin{array}{l}93,6: 6.4 \\
95,2: 4,8 \\
96,7: 3,3\end{array}$ & $\begin{array}{l}0,30 \\
0,97 \\
1.1\end{array}$ & $\begin{array}{r}9 \\
23 \\
45\end{array}$ & $\begin{array}{l}25,0 \\
25,2 \\
25,1\end{array}$ & $\begin{array}{l}94,8: 5,2 \\
95,4: 4,6 \\
95,2: 4,8\end{array}$ & $\begin{array}{l}1,02 \\
1,05 \\
1.0\end{array}$ \\
\hline
\end{tabular}

* Первоначально загружали в реакционный сосуд смесь мономеров в соотношении АН : МА $=99,5: 0,5 \%$ мол. и окислитель, затем дозировали смесь мономеров в соотношении 98,5: 4,5\% мол., восстановитель и регулятор.

По данным, прнведенным в табл. 1, при дробной дозировке мономеров получает:я сополимер, более однородный по химическому составу и молекулярному весу. Концентрированные растворы сополимера ПАНМ, полученного по вышеуказанному мето-

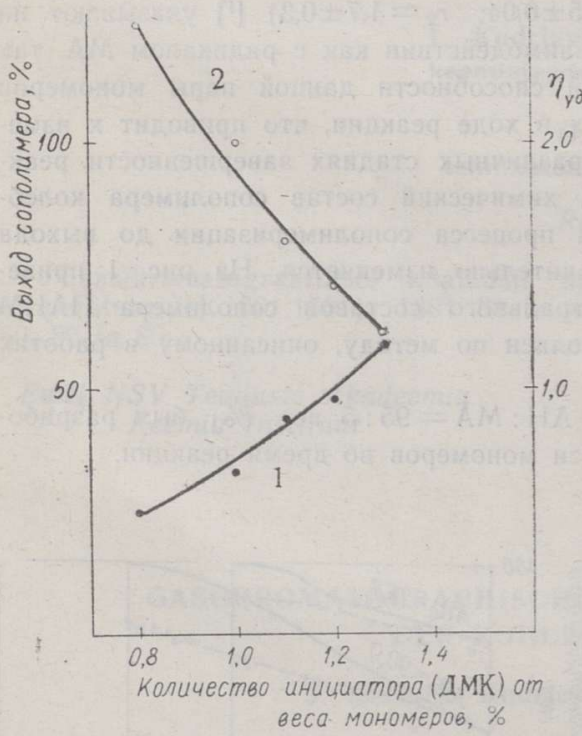

Рис. 2. Влияние количества инициатора на выход и удельную вязкость сополимера (время 3,5 час, температура $63^{\circ} \mathrm{C}$, исходный состав смеси мономеров $\mathrm{AH}: \mathrm{MA}=96,7: 3,3 \%$ мол.). $1=$ выход сополимера; 2 - удельная вяз-

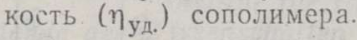
ду, обладают относительно низкой стабиль ностью. С течением времени происходит зна$\eta$ чительное повышение вязкости растворов вплоть до гелеобразования. Так, например, ,0 свежеприготовленный $13 \%$-ный раствор сополимера $\left(\eta_{\text {уд. }}=1,25\right)$ имеет вязкость 108 сек, а по истечению 3 суток его вязкость повышается до 500 сек. Причины, вызы вающие измененке вязкости раствора, нами не исследовались. Инициирование реакщии сополимеризации осуцествлялось окисли тельно-восстановительной системой, содер жащей соли серебра. Несмотря на тщательную промывку сополимера, следы солей серебра остаются в нем и они, ло-видимому, вызывают снижение устойчивости раствора полимера.

Учитывая это обстоятельство, в дальнейшем в качестве инициатора применяли динитрила азоизомасляной кислоты (ДМК). В этом случае реакция сополимеризации проводилась в бензоле, при перемешивании в атмосфере аргона. Исследовалось влияние количества инициатора и времени на выход и молекулярный вес сополимера. Данные исследования приведены на рис. 2 .

Если в сополимере, полученном при помоши окислительно-восстановительной си стемы при температуре от 20 до $40^{\circ} \mathrm{C}$, составы, определенные по содержанию азота и альдегидных групп, приблизительно совпадали, то в сополимере, полученном по описанному выше методу, содержание альдегидных групп составляет $\sim 50 \%$ от их коли- 
чества, рассчитанного по содержанию азота. Очевидно, при температуре реакции $-60^{\circ}$ сильно повышается перенос цепи, приводящий к образованию винилкетонных концевых групп (реакция і) или получению разветвленного полимера (реакщия 2).

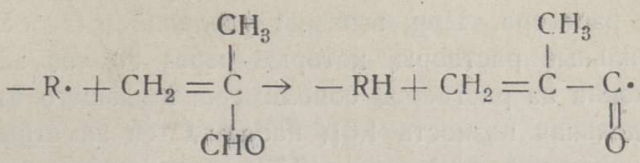

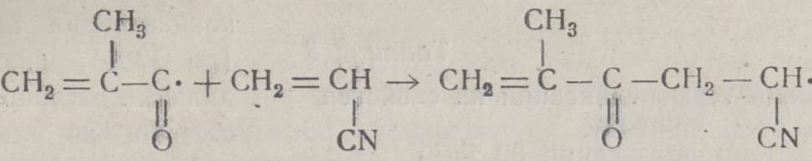

$$
\begin{aligned}
& -\mathrm{R} \cdot+-\mathrm{CH}_{2} \underset{\mathrm{CHO}}{\stackrel{+}{\mathrm{C}}-\mathrm{CH}_{3}} \rightarrow-\mathrm{RH}+-\mathrm{CH}_{2}-\stackrel{!}{\mathrm{C}}-
\end{aligned}
$$

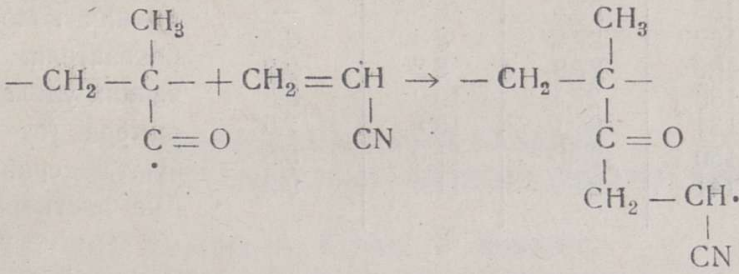

Применяя в качестве инициатора окислительно-восстановительную систему и ДМК, были получены сополимеры заданного состава и молекулярного веса. Для формования волокон готовились прядильные растворы сополимеров в диметилформамиде (ДМФ) с вязкостью 30-110 сек. Волокно формовалось в условиях, аналогичных условиям формования ПАН-волокна, . по водно-диметилформамидному методу.

таблийа 2

Влияние молекулярного веса сополимера на свойства волокна

\begin{tabular}{|c|c|c|c|c|c|c|c|c|c|}
\hline $\begin{array}{l}\text { № } \\
\text { II. }\end{array}$ & $\begin{array}{c}\text { Состав сопо- } \\
\text { лимера } \\
(\mathrm{AH}: \mathrm{MA}) \\
\text { вес. } \%\end{array}$ & $\mid \begin{array}{c}\text { Удельная } \\
\text { вязкость } \\
\left(\eta_{\text {уд. })}\right.\end{array}$ & $\begin{array}{l}\text { Концент- } \\
\text { рация } \\
\text { прядиль- } \\
\text { ного раст- } \\
\text { вора, \% }\end{array}$ & $\begin{array}{c}\text { Вязкость } \\
\text { прядиль- } \\
\text { ного раст- } \\
\text { вора, } \\
\text { сек }\end{array}$ & $\begin{array}{c}\text { I } \\
\text { Вытяж- } \\
\text { ка, \% }\end{array}$ & $\begin{array}{c}\text { II } \\
\text { Вытяж- } \\
\text { ка, \% }\end{array}$ & $\begin{array}{c}\text { Номер } \\
\text { волок- } \\
\text { на }\end{array}$ & $\begin{array}{l}\text { Проч- } \\
\text { ность, } \\
\text { ркм }\end{array}$ & 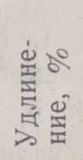 \\
\hline $\begin{array}{l}1 \\
2 \\
3 \\
4 \\
5 \\
6 \\
7 \\
8 \\
9 *\end{array}$ & $\begin{array}{l}88,8: 11,2 \\
87,0: 11,2 \\
87,0: 13,0 \\
87,0: 13,0 \\
87,0: 13,0 \\
87,0: 13,0 \\
94,0: 6,0 \\
94,0: 6,0 \\
96,0: 4,0\end{array}$ & $\begin{array}{l}1,60 \\
1,60 \\
1,37 \\
1,37 \\
1,22 \\
1,22 \\
0.77 \\
0,77 \\
1,28\end{array}$ & $\begin{array}{l}15 \\
15 \\
15 \\
15 \\
15 \\
15 \\
17 \\
17 \\
13\end{array}$ & $\begin{array}{r}100 \\
100 \\
60 \\
60 \\
50 \\
50 \\
33 \\
33 \\
108\end{array}$ & $\begin{array}{r}350 \\
350 \\
635 \\
635 \\
635 \\
635 \\
350 \\
350 \\
450\end{array}$ & $\begin{array}{l}\frac{\overline{18}}{18} \\
\frac{18}{18} \\
\frac{18}{18}\end{array}$ & $\begin{array}{r}61 \\
81 \\
98 \\
114 \\
120 \\
139 \\
93 \\
110 \\
74\end{array}$ & $\begin{array}{l}17,8 \\
22,8 \\
21,0 \\
23,0 \\
27,5 \\
29,2 \\
17,0 \\
24,0 \\
29,6\end{array}$ & $\begin{array}{l}6,0 \\
7,6 \\
6,0 \\
7,0 \\
6,6 \\
6,8 \\
4,4 \\
7,0 \\
9,4\end{array}$ \\
\hline
\end{tabular}

* Сополимер синтезирован в водной среде с дополнительной дозировкой смеси мономеров.

В качестве осадительной ванны применялся $60 \%$-ный водный раствор ДМФ с температурой $10-50^{\circ}$. Волокна формовались на опытном стенде при отрицательной фильерной вытяжке $(-47 \%)$. Первая вытяжка проводилась в ванне с горячей водой при 
$-97^{\circ}$, дополнительная вытяжка при $170^{\circ}$ в глицериновой ванне. Применялись сополимеры (удельная вязкость от 0,77 до 1,60) молекулярные веса которых, определенныс по осмометрическому методу, изменялись в пределах от 25000 до 41000 .

На показатели свойств волокон из сополимера существенное влияние оказывают свойства прядильного раствора. При высокой удельной вязкости сополимера $(1,6)$ получаются малостабнльные растворы, которые через 30 час застудневают. В процессе формования волокна из растворов сополимера, имеющего относительно большой молекулярный вес (удельная вязкость 1,6), наблюдается заметный засор фильер. Из сополимера с низкой удельной вязкостью $(0,77)$ получаются, даже при повышенной

Таблица 3 концентрации его в растворе (до $17 \%$ ), низковязкие пря-

Влияние условий терморелаксации на свойства волокна

(время терморелаксашии 30 мин)

\begin{tabular}{c|c|c|c|c|c}
\hline № & $\begin{array}{c}\text { Tемпе- } \\
\text { ратура, } \\
\text { п्ट. }\end{array}$ & $\begin{array}{c}\text { Номер } \\
\text { волокна }\end{array}$ & $\begin{array}{c}\text { Проч- } \\
\text { ность, } \\
\text { ркм }\end{array}$ & $\begin{array}{c}\text { Удлине- } \\
\text { ние, \% }\end{array}$ & $\begin{array}{c}\text { Усадка, } \\
\%\end{array}$ \\
\hline & & & & & \\
1 & - & 165 & 27,5 & 6,5 & \\
2 & 80 & 162 & 27,6 & 8,0 & 0,7 \\
3 & 100 & 160 & 27,9 & 8,2 & 2,0 \\
4 & 120 & 156 & 27,1 & 10,0 & 6,5 \\
5 & 140 & 154 & 26,1 & 10,8 & 7,6 \\
6 & 160 & 150 & 25,5 & 11,0 & 8,8 \\
7 & кипящая & 141 & 24,0 & 11,4 & 9,2 \\
& вода & & & &
\end{tabular}

дильные растворы. Формование волокон из таких растворов протекает неустойчиво. В результате того, что из сополимеров с низкой и высокой удельной вязкостью получаются недостаточно качественные прядильные растворы, полученные из них волокна имеют низкие показатели. При средних значениях удельной вязкости сополимера (от 1,2 до 1,3) образуются сравнительно стабильные растворы. Благодаря этому заметно улучшается процесо формования волокна, в результате чего получаются волокна с более высской прочностью (см. табл. 2). Для улучшения механических свойств волокна подвергались термообработкам. Терморелаксация проводилась в свободном состоянии в горячем роздухе при разных температурах и в кигящей воде. Данные опытов приведены в табл. 3.

При терморелаксации происходит усадка волокна. При этом заметіо увелинивается удлинение, в то время как прочность почти не изменяется.

\section{Выводы}

1. Найдены условия синтеза волокнообрдзующего сополимера АН с МА, содержащего 10-13 вес. \% МА в растворе мсномеров в бензоле.

2. Получены волокна на базе сополимера ПАНМ с разрывной длиной $17-29 \mathrm{~km}$ и удлинением $10-11 \%$ (после терморелаксации).

\section{Л И Т Е Р А Т У Р А}

1. Қольк А. Р., Роговин 3. А., Қонкин А. А., Хим. волокна, № 4, 12 (1963).

2. Дюрнб аум В. С., Абкин А. Д., Клименков В. С., Хим. волокна, № 2, 10 (1962).

3. Гиндин Л., Абкин А. Д., Медведев С., ЖФХ, вып. 2, 21, 1219 (1947).

Ннститут химии

Академии наук Эстонсксй ССР
Поступила в редакцию

6. V 1964 


\title{
KIU SAAMINE AKRUULNITRIILI JA METAKROLEIINI KOPOLÜMEERIST
}

A. Kolk

A. Konkin, Z. Rogovin, tehnikateaduste doktorid

Resümee

Töös käsitletakse kiudu andva akrüülnitriili ja metakroleiini kopolümeeri sünteesi. See teostati kahel meetodil: 1) monomeeride vesilahuses redokssüsteemi $\mathrm{K}_{2} \mathrm{~S}_{2} \mathrm{O} 8+\mathrm{AgNO}_{3}$ manuiusel, kusjuures monomeeride segu reaktsiooni käigus pidevalt doseeriti; 2) monomeericie bensoolilahuses initsiaatori asoisovõihappe dinitriili manulusel.

Arvutuse teel määrati kopolümeeri integraalsed ja diferentsiaalsed koosseisud.

Kiu ketramisel surutakse ketruslahus (12-18\% kopolümeeri dimetüülformamiidis) koagulatsioonivanni, mis sisaldab $40 \%$ vett ja $60 \%$ dimetüülformamiidi. Optimaalne kopolümeeri molekulkaal on 35000 .

Saadud kiud on küllaldaselt heade mehaaniliste omadustega: katkemispikkus $17-29 \mathrm{~km}$ ja pikenemine $10-12 \%$ (pärast termorelaksatsiooni).

\author{
Eesti NSV Teaduste Akadeemia \\ Keemia Instituut \\ Saabus toimetusse \\ 6. V 1964
}

\section{HERSTELLUNG VON FASERN \\ AUS DEM, ACRYLNITRIL-METACROLEINCOPOLYMER}

\author{
A. Kolk, A. Konkin, Z. Rogowin
}

\section{Zusammenfassung}

Die Arbeit behandelt eine Synthese des Acrylnitril-Metacroleincopolymers. Diese Synthese wurde mittels zweier Methoden erzielt, und zwar 1) in einer Wasserlösung der Monomere, in Anwesenheit des Redoxsystems $\mathrm{K}_{2} \mathrm{~S}_{2} \mathrm{O} 8+\mathrm{AgNO}_{3}$ mit fortlaufender Dosierung der Monomerenmischung während des gesamten Reaktionsprozesses, 2) in einer Benzollösung der Monomere, wobei das Dinitril der Azoisobuttersäure die Rolle des Initiators spielte.

Die integralen und differentialen Zusammensetzungen des Copolymers wurden rechnerisch festgestellt.

Die Spinnlösung (12-18\% Copolymer im Dimethylformamid) wird in ein Koagulationsbad, das $40 \%$ Wasser und $60 \%$ DMF enthält, hineingepresst. Das optimale Molekulargewicht des Copolymers ist 35000 .

Die auf diesein Wege entstandene Faser besitzt recht befriedigende mechanische Eigeischaften, und zwar: Reissfestigkeit - 17-29 km, Dehnung - 10-12\% (nach der Thermorelaxation). 